\title{
A dizziness questionnaire is helpful when assessing patients with dizziness in the telephone consultations during the COVID-19 pandemic
}

\author{
Anna Kaleva ${ }^{1}$, Laura Leach ${ }^{2}$, F. Fahmy ${ }^{3}$, Lucy Truman ${ }^{4}$, and Marcos Martinez Del Pero ${ }^{5}$ \\ ${ }^{1}$ Luton \& Dunstable NHS Trust \\ ${ }^{2}$ Department of Otorhinolaryngology, Peterborough City Hospital, North West Anglia NHS \\ Foundation Trust, UK \\ ${ }^{3}$ West Suffolk \& Addenbrooke's Hospitals \\ ${ }^{4}$ Addenbrooke's Hospital \\ ${ }^{5}$ Cambridge Teaching Hospitals
}

October 28, 2020

\begin{abstract}
Background: In March 2020, in response to the COVID19 outbreak, ENT UK issued guidance recommending that all routine clinics should be cancelled and telephone review should be the first approach for all outpatients who do not need urgent treatment. Our district general hospital department therefore organised telephone reviews for all patients referred with dizziness. It was decided to trial a questionnaire to help clinicians with this new approach to assessing patients with dizziness. Study Design: Prospective Single Centre Randomised Pilot Study. Methods: Local ethics approved was obtained and all 115 patients awaiting otolaryngological assessment for balance were randomised to receive a validated dizziness questionnaire or not. Questionnaires were posted to the patients prior to their appointment. They were then contacted for a planned telephone consultation for dizziness. Data on the outcome and effectiveness of the consultation was collected by the clinicians conducting the consultation. Results were analysed using Microsoft Excel and Fisher's exact test was used for the statistical analysis. Results: 82/115 patients had consultations with complete data collection, 35 in the questionnaire group (QG) and 47 in the no questionnaire group (NQG). Response rate (returned completed questionnaires) in the QG was 70\%. Clinicians were able to make a provisional diagnosis in $77 \%$ of QG patients vs $57 \%$ of NQG patients. QG patients only required additional investigations $26 \%$ of the time compared to $72 \%$ in the NQG $(\mathrm{p}<0.05)$. Only $17 \%$ of QG patients needed additional telephone follow up, compared to $43 \%$ of NQG patients $(\mathrm{P}<0.05)$. Conclusion: Using an abbreviated dizziness questionnaire can increase clinicians' ability to come to a diagnosis at the end of a telephone consultation. It may reduce the need for additional investigations and further telephone follow-up, thereby keeping patients away from the hospital and freeing up capacity.
\end{abstract}

A dizziness questionnaire is helpful when assessing patients with dizziness in the telephone consultations during the COVID-19 pandemic

Running Title: Dizziness Questionnaire Paper

\section{Abstract}

Objectives: In response to the ENT UK guidance at the start of the COVID-19 outbreak to cancel all routine clinics and give patients telephone reviews, the ENT department at the West Suffolk Hospital decided to trial a questionnaire to help clinicians with telephone assessment of patients with dizziness. This study aimed to assess what effect introducing a questionnaire had on the telephone consultation outcomes. 
Study Design: Prospective Single Centre Randomised Pilot Study using the Roland Dizziness Questionnaire (RDQ)(1).

Participants: All 115 patients awaiting otolaryngological assessment for balance were randomised to receive a validated dizziness questionnaire or not.

Main Outcome Measures: Consultation outcomes recorded: ability to come to a diagnosis, need for investigations, need for additional follow up and onward referral to other specialties.

Results and Conclusions: 82/115 patients had consultations with complete data collection, 35 in the questionnaire group (QG) and 47 in the no questionnaire group (NQG). Response rate (returned completed questionnaires) in the QG was $70 \%$. Clinicians came to a provisional diagnosis in $77 \%$ of QG patients vs $57 \%$ of NQG patients. QG patients only required additional investigations $26 \%$ of the time compared to $72 \%$ in the NQG $(\mathrm{p}<0.05)$. Only $17 \%$ of $\mathrm{QG}$ patients needed additional telephone follow up, compared to $43 \%$ of NQG patients $(\mathrm{P}<0.05)$.

Using an abbreviated dizziness questionnaire increased clinicians' ability to come to a diagnosis at the end of a telephone consultation. It reduced the need for additional investigations and further telephone follow-up, thereby keeping patients away from the hospital and freeing up capacity.

\section{Key points}

- The RDQ helped clinicians make a diagnosis in patients with dizziness

- The use of the RDQ reduced the need for additional investigations and further telephone follow-up

- The use of the RDQ does not significantly reduce the need for face-to-face appointments

- The use of a questionnaire does not increase the rate of discharges of patients straight after the initial telephone consultation

- Both patients and clinicians reported the RDQ was a useful addition to the assessment

\section{Introduction}

On March $20^{\text {th }} 2020$, ENT UK messaged all its members recommending that all routine clinics should be cancelled and telephone review should be the first approach for all outpatients who do not need urgent treatment(2). As seen in other countries(3), our ear, nose and throat (ENT) department wanted to try and reduce delays and distress to patients by impact by offering telephone assessments for suitable patients. Dizziness, has an estimated lifetime prevalence of 30\%(4) and can be diagnosed from medical history(5-7) alone, making dizzy patients potentially suitable for telephone clinics.

Dizziness prevalence increases with age(8) and this is reflected in the patient demographic of patients referred to our centre. COVID-19 is more severe in older patients(9), hence it was even more important to reduce exposure of this population with the hospital environment where the risk of infections is highest.

We wanted to know if a questionnaire would make assessment and diagnosis of vestibular disorders easier over the telephone A number of studies have used questionnaires to facilitate diagnosis in patients complaining of dizziness $(10,11)$ but most of these have focused on one specific diagnosis e.g. BPPV ${ }^{10}$ or hyperventillation ${ }^{11}$. Others have looked at using questionnaire to assess severity of pathology $(12,13)$. We chose a dizziness questionnaire described by Roland et al(1) because it was short, validated by its developers and is able to differentiate peripheral vestibular pathology from other causes of dizziness(1). Such a distinction could enable clinicians to decide whether patients need further investigations, a face-to-face appointment, or referral to another specialty. This has the potential to reduce the number of visits to the hospital for each patient.

The objective of this study was to assess whether use of the Roland et al(1) dizziness questionnaire (RDQ) facilitated diagnosis, reduced the number of investigations and face-to-face appointments, increases discharges and whether it is helpful to clinicians and patients using it.

\section{Methods}


Ethical Considerations: A project proposal for a randomised prospective study titled 'Utility of A Dizziness Questionnaire in ENT Balance Assessments in Times of COVID-19' was submitted and approved by the local Research Operational Committee (ROC) at West Suffolk Hospital.

Participants: All 115 patients who were awaiting a first balance assessment were included in the study. Using Microsoft Excel number generator, patients were randomised to being sent an RDQ in the post or not. 57 patients were randomised to receive a questionnaire (questionnaire group (QG)) and 58 patients did not receive a questionnaire (non-questionnaire group (NQG). The RDQ asks patients 7 sets of close-ended questions regarding their dizziness spells, hearing, other ear symptoms, and any additional symptoms. The 57 patients who were randomised to receiving the RDQ received a letter in the post asking them to complete the questionnaire and return it using a pre-stamped and addressed envelope. If returned in time, the clinician conducting the telephone consultation would read this prior to the consultation. Fifty-eight patients were randomised to not receiving anything in the post.

All telephone consultations were timed and at the end of each consultation a survey s was completed by the clinician. Any patients in the QG who did not return their completed questionnaire were excluded from analysis. Also, any patients where the clinician did not complete the data collection tool were also excluded.

Analysis: The results were then analysed using Microsoft Excel. The response rate (returned completed questionnaires) in the QG was $70 \%$ so this was considered a representative sample. As the results constituted categorical data with a small sample size, Fisher's exact test was used to assess for a statistical difference between the two groups. A p-value of $<0.05$ was considered significant.

\section{Results}

115 patients were randomised, 57 to receive a questionnaire (questionnaire group QG) and 58 to not receive a questionnaire (non-questionnaire group NQG) (See Figure 1). All patients were contacted and offered a telephone consultation for their balance complaint. Some patients were not contactable or declined the consultation as their problem had resolved. In the QG 40/57patients completed and returned the questionnaire in the envelopes provided, giving a response rate of $70 \%$. Five of these patients' questionnaire arrived in the post after their appointment, but as they had completed it which likely affected their ability to articulate their symptoms, they were included in the study. Thirty-five 35/57 (61\%) patients in the QG and 47/58 (81\%) patients in the NQG were included in the analysis. The age range of patients was $13-95$ years with a mean age of 59 years old. Fifty-seven patients were female 57/82 (70\%) of the patients were female. Five different clinicians conducted the consultations, three consultants and two specialist registrars. Fifty-two patients, 52/85 (61\%) of patients had their consultation with an ENT consultant and 33/85 (39\%) with a specialty registrar. In the QG 22/38 (51\%) were seen by a consultant whilst in the NQG 30/47 (64\%) patients were seen by a consultant. The mean duration of telephone consultations was 13 mins (range $3-31$ mins) with no difference between the two groups $(\mathrm{p}=1)$. 


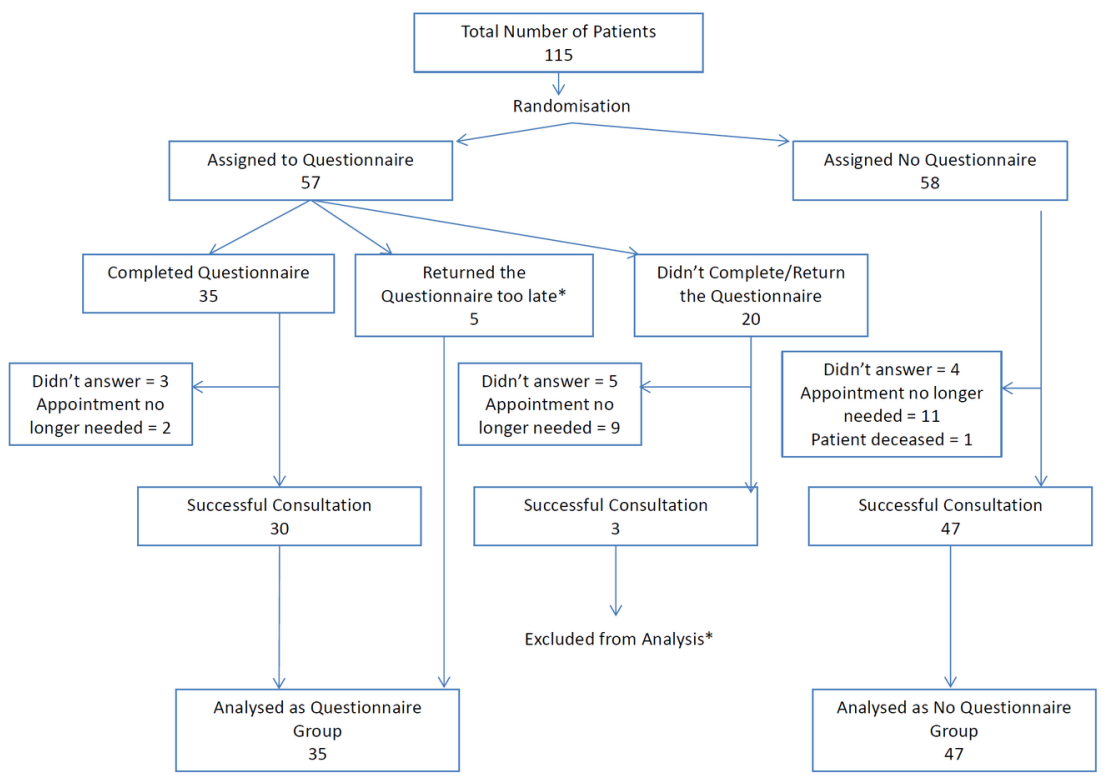

Figure 1. Consort Diagram

In the QG the likelihood that the clinician would make a diagnosis was $77 \%$, higher than in the NQG, $57 \%$ but this did not reach statistical significance, $\mathrm{p}=0.0555$ (Table 1). The two most common diagnoses were Benign Paroxysmal Positional Vertigo (BPPV) 18/85 (21\%) and Vestibular Migraine 16/85 (20\%) (Figure 2 ). There was no significant difference in the distribution of diagnoses made in the two groups . Clinicians requested additional investigations, such as MRI scans, for 9/35 (26\%) of patients in the QG, compared to $34 / 47(72 \%)$ patients in the NQG, and this difference was statistically significant $\mathrm{p}=0.0409$. A bigger proportion of QG patients were referred for vestibular physiotherapy 6/35 (17\%), than in the NQG 6/47 (13\%). After the initial telephone consultation, 18/35 (51\%) of QG patients were discharged compared to $19 / 47(40 \%)$ in the NQG. There were significantly fewer telephone follow-up consultations requested in the QG, 6/35 (17\%), compared to the NQG 20/47 (43\%), $\mathrm{p}=0.0173$. 


\begin{tabular}{|c|c|c|c|}
\hline 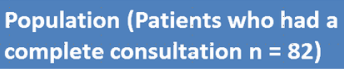 & $\begin{array}{l}\text { Questionnaire group } \\
(n=35)\end{array}$ & $\begin{array}{l}\text { No Questionnaire Group } \\
(n=47)\end{array}$ & $\begin{array}{l}\text { P-value (if } \\
\text { available) }\end{array}$ \\
\hline $\begin{array}{l}\text { Age Range }=13-95 \text { years } \\
\text { Age Mean }=59 \\
\text { Age Median }=62\end{array}$ & $\begin{array}{l}13-83 \text { years } \\
58 \\
58\end{array}$ & $\begin{array}{l}25-95 \text { years } \\
60 \\
68\end{array}$ & \\
\hline Female $=57(70 \%)$ & $23(66 \%)$ & $34(73 \%)$ & 0.629 \\
\hline $\begin{array}{l}\text { Duration of Consultation (mins) } \\
\text { Mean }=13 \\
\text { Median }=14\end{array}$ & $\begin{array}{l}13 \\
14\end{array}$ & $\begin{array}{l}13 \\
13\end{array}$ & 1 \\
\hline $\begin{array}{l}\text { Able to make a Diagnosis over } \\
\text { Telephone } \%=66 \%\end{array}$ & $27(77 \%)$ & $27(57 \%)$ & 0.0986 \\
\hline $\begin{array}{l}\text { Patient required an additional } \\
\text { face-to-face appointment }=23 \%\end{array}$ & $11(31 \%)$ & $8(17 \%)$ & 0.1855 \\
\hline $\begin{array}{l}\text { Patients required additional } \\
\text { investigations }=39 \%\end{array}$ & $9(26 \%)^{*}$ & $34(72 \%)^{*}$ & $0.0409^{*}$ \\
\hline $\begin{array}{l}\text { Patients were referred for } \\
\text { vestibular physiotherapy }=15 \%\end{array}$ & $6(17 \%)$ & $6(13 \%)$ & 0.7536 \\
\hline $\begin{array}{l}\text { Patients discharged after the } \\
\text { telephone consultation }=45 \%\end{array}$ & $18(51 \%)$ & $19(40 \%)$ & 0.3736 \\
\hline $\begin{array}{l}\text { Patients required additional } \\
\text { telephone follow-up }=32 \%\end{array}$ & $6(17 \%)^{*}$ & $20(43 \%)^{*}$ & $0.0173^{*}$ \\
\hline *Statistically significant & & & \\
\hline
\end{tabular}

Table1. Telephone consultation outcomes

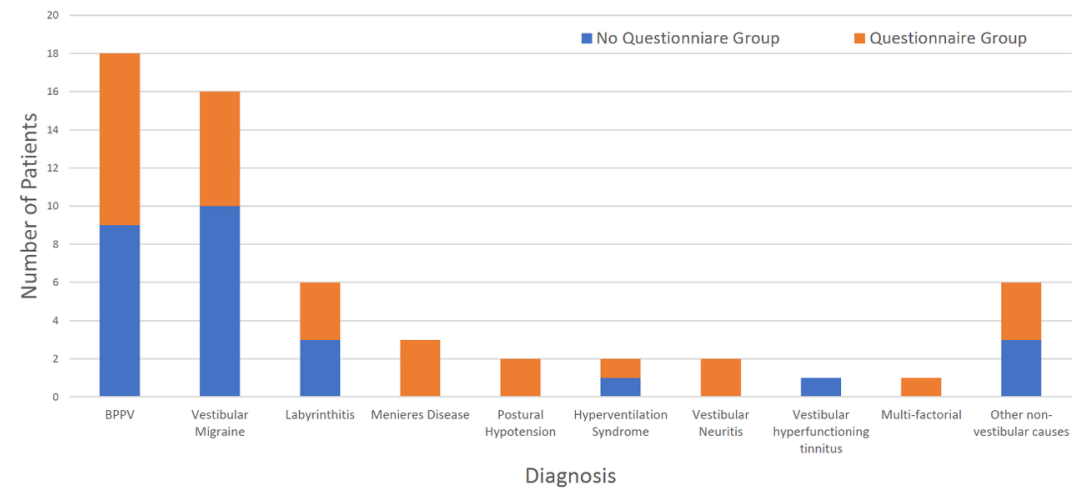

Figure 2. Diagnoses made

Across both groups, specialty registrars were significantly more likely to refer patients for vestibular physiotherapy, $9 / 33(27 \%)$ of the time vs. $3 / 52(6 \%)$ of the time for consultants $(\mathrm{p}=0.0091)$. Whilst consultants, were significantly less likely to request any investigations for patients in the QG 2/20 (10\%) versus 14/30 $(47 \%)$ in the NQG, $\mathrm{p}=0.0055)$. The difference in likelihood of requesting an investigation was not observed in the specialty registrar consultations. There were no differences in observed outcomes in either group between specialty registrars and consultants when it came to making a diagnosis, requesting additional face-to-face appointments, discharging patients and requesting telephone follow-up.

Sixteen patients who received and returned a completed questionnaire 16/35 (46\%) found the questionnaire a positive addition to their consultation, $3 / 35(9 \%)$ did not find it a positive addition and 16/35 (46\%) were unsure. The clinicians found the questionnaire helped the consultation $24 / 35(69 \%)$ of the time and thought 
that in $22 / 35(63 \%)$ of cases, they would have found the questionnaire helpful even in a pre-COVID19, face-to-face consultation.

\section{Discussion}

The COVID-19 pandemic will influence our clinical ENT practice in the long-term. This gives us an opportunity to explore new ways to care for our patients. The lockdown measures in the UK have had significant negative effects on the capacity to deliver healthcare and across the National Health Service, clinicians have had to adapt to the infection control and social distancing measures. Increasingly virtual clinics are being introduced in secondary care e.g. in Orthopaedics there is evidence that is largely acceptable to patients(14). Even prior to the COVID-19 outbreak, clinicians in primary care had started adopting telemedicine and started to investigate how to deliver this in a high quality, accessible and affordable manner(15). There is evidence that digital healthcare may be more convenient and patient-centred and therefore bring many advantages(16). Other studies have shown that diagnosis of peripheral vestibular pathology e.g. BPPV and vestibular migraine, made by telephone interview compares favourably with subsequent diagnoses made by neuro-otologists in the face-to-face clinic(17). The study described here investigated whether telephone consultations for patients with dizziness had different outcomes when a diagnostic questionnaire was used and whether it changed the onward management of patients. The findings suggest that the questionnaire helped clinicians make a diagnosis, reduced the need for additional investigations and reduced telephone follow-up.

A number of questionnaires have been used in the management of dizziness such as the dizziness handicap inventory (DHI)(13) and the University of California, Los Angeles Dizziness Questionnaire (UCLA-DQ)(18). The usefulness of these questionnaires has been reviewed in the literature, both as a way of assessing patients and assessing effectiveness of interventions $(18,19)$. There are relatively fewer studies looking specifically at using a questionnaire to help diagnose causes of dizziness(20). The results described above comprise the first report looking specifically at the usefulness of a questionnaire in telephone consultations, and is particularly relevant given the increase in telephone consultations occurring during the COVID-19 pandemic. These results show that using the Roland dizziness questionnaire (RDQ) as an adjunct to telephone consultations reduced the need for patients to come into hospital for face to face consultations and reduced the number of investigations ordered and reduced the number of telephone follow up appointments. At our hospital we found that an initial telephone consultation frees up ENT outpatient capacity for face to face consultations that can be used for conditions that need visual assessment, such as patients with hoarseness or suspicion of cholesteatoma.

However, the results described above do not suggest that the questionnaire changes the rate of requests for further face-to-face ENT assessments. This may be because conditions such as Benign Paroxysmal Positional Vertigo (BPPV), require face-to-face diagnosis and treatment (Dix-Hallpike and Epley manoeuvres respectively). For other vestibular pathology e.g. persistent postural-perceptual dizziness (PPPD) there is evidence that treatment can be delivered by telephone and it is acceptable to patients(21). Therefore it is possible that in the future many more treatments, including for conditions such as (BPPV), could be delivered by tele-medicine as well e.g. by developing devices such as a cell phone balance trainer(22).

Other studies have described the patient perceptions of telemedicine as applied to ENT practice during the COVID-19 pandemic(23-25). We did not include a formal assessment of patient perception and satisfaction with the telephone consultation in our study. But we did ask both patients and clinicians about usefulness of the questionnaire in our study. Since telemedicine has been adopted out of necessity during the COVID-19 pandemic, $46 \%$ of patients finding the questionnaire useful, brings us a big step closer to the acceptance of 'the new normal' for patients. In an even bigger proportion of consultations, $69 \%$, clinicians found the questionnaire helpful, showing the usefulness of this questionnaire clinically.

\section{Conflict of interests}

The authors declare that they have no conflict of interest. 


\section{Ethical Approval}

The study was approved by the local Research Operational Committee (ROC) at West Suffolk Hospital.

1. Roland LT, Kallogjeri D, Sinks BC, Rauch SD, Shepard NT, White JA, et al. Utility of an Abbreviated Dizziness Questionnaire to Differentiate Between Causes of Vertigo and Guide Appropriate Referral: A Multicenter Prospective Blinded Study. Otol Neurotol. 2015;36(10):1687-94.

2. N. Kumar CH, P Tostevin and A Swift. ENT UK Covid - 19 letter to members, Friday 20 March. 2020.

3. Triantafillou V, Rajasekaran K. A Commentary on the Challenges of Telemedicine for Head and Neck Oncologic Patients during COVID-19. Otolaryngol Head Neck Surg. 2020;163(1):81-2.

4. Neuhauser HK, von Brevern M, Radtke A, Lezius F, Feldmann M, Ziese T, et al. Epidemiology of vestibular vertigo: a neurotologic survey of the general population. Neurology. 2005;65(6):898-904.

5. Welgampola MS, Bradshaw AP, Halmagyi GM. Assessment of the Vestibular System: History and Physical Examination. Adv Otorhinolaryngol. 2019;82:1-11.

6. Wuyts FL, Van Rompaey V, Maes LK. "SO STONED": Common Sense Approach of the Dizzy Patient. Front Surg. 2016;3:32.

7. Radtke A, von Brevern M, Feldmann M, Lezius F, Ziese T, Lempert T, et al. Screening for Meniere's disease in the general population - the needle in the haystack. Acta Otolaryngol. 2008;128(3):272-6.

8. Neuhauser HK. Epidemiology of vertigo. Curr Opin Neurol. 2007;20(1):40-6.

9. Nikolich-Zugich J, Knox KS, Rios CT, Natt B, Bhattacharya D, Fain MJ. SARS-CoV-2 and COVID-19 in older adults: what we may expect regarding pathogenesis, immune responses, and outcomes. Geroscience. 2020;42(2):505-14.

10. Kim HJ, Song JM, Zhong L, Yang X, Kim JS. Questionnaire-based diagnosis of benign paroxysmal positional vertigo. Neurology. 2020;94(9):e942-e9.

11. van Dixhoorn J, Duivenvoorden HJ. Efficacy of Nijmegen Questionnaire in recognition of the hyperventilation syndrome. J Psychosom Res. 1985;29(2):199-206.

12. Yagi C, Morita Y, Kitazawa M, Nonomura Y, Yamagishi T, Ohshima S, et al. A Validated Questionnaire to Assess the Severity of Persistent Postural-Perceptual Dizziness (PPPD): The Niigata PPPD Questionnaire (NPQ). Otol Neurotol. 2019;40(7):e747-e52.

13. Jacobson GP, Newman CW. The development of the Dizziness Handicap Inventory. Arch Otolaryngol Head Neck Surg. 1990;116(4):424-7.

14. Gilbert AW, Billany JCT, Adam R, Martin L, Tobin R, Bagdai S, et al. Rapid implementation of virtual clinics due to COVID-19: report and early evaluation of a quality improvement initiative. BMJ Open Qual. $2020 ; 9(2)$.

15. van der Kleij R, Kasteleyn MJ, Meijer E, Bonten TN, Houwink EJF, Teichert M, et al. SERIES: eHealth in primary care. Part 1: Concepts, conditions and challenges. Eur J Gen Pract. 2019;25(4):179-89.

16. Mitchell M, Kan L. Digital Technology and the Future of Health Systems. Health Syst Reform. 2019;5(2):113-20.

17. von Brevern M, Radtke A, Lezius F, Feldmann M, Ziese T, Lempert T, et al. Epidemiology of benign paroxysmal positional vertigo: a population based study. J Neurol Neurosurg Psychiatry. 2007;78(7):710-5.

18. Honrubia V, Bell TS, Harris MR, Baloh RW, Fisher LM. Quantitative evaluation of dizziness characteristics and impact on quality of life. Am J Otol. 1996;17(4):595-602. 
19. Zur O, Carmeli E. The University of California Los Angeles Dizziness Questionnaire: advantages and disadvantages. J Vestib Res. 2013;23(6):279-83.

20. Zhao JG, Piccirillo JF, Spitznagel EL, Jr., Kallogjeri D, Goebel JA. Predictive capability of historical data for diagnosis of dizziness. Otol Neurotol. 2011;32(2):284-90.

21. Thompson KJ, Goetting JC, Staab JP, Shepard NT. Retrospective review and telephone follow-up to evaluate a physical therapy protocol for treating persistent postural-perceptual dizziness: A pilot study. J Vestib Res. 2015;25(2):97-103; quiz -4.

22. Lee BC, Kim J, Chen S, Sienko KH. Cell phone based balance trainer. J Neuroeng Rehabil. 2012;9:10.

23. Triantafillou V, Layfield E, Prasad A, Deng J, Shanti RM, Newman JG, et al. Patient Perceptions of Head and Neck Ambulatory Telemedicine Visits: A Qualitative Study. Otolaryngol Head Neck Surg. 2020:194599820943523.

24. Strohl MP, Dwyer CD, Ma Y, Rosen CA, Schneider SL, Young VN. Implementation of Telemedicine in a Laryngology Practice During the COVID-19 Pandemic: Lessons Learned, Experiences Shared. J Voice. 2020.

25. Maurrasse SE, Rastatter JC, Hoff SR, Billings KR, Valika TS. Telemedicine During the COVID-19 Pandemic: A Pediatric Otolaryngology Perspective. Otolaryngol Head Neck Surg. 2020;163(3):480-1.

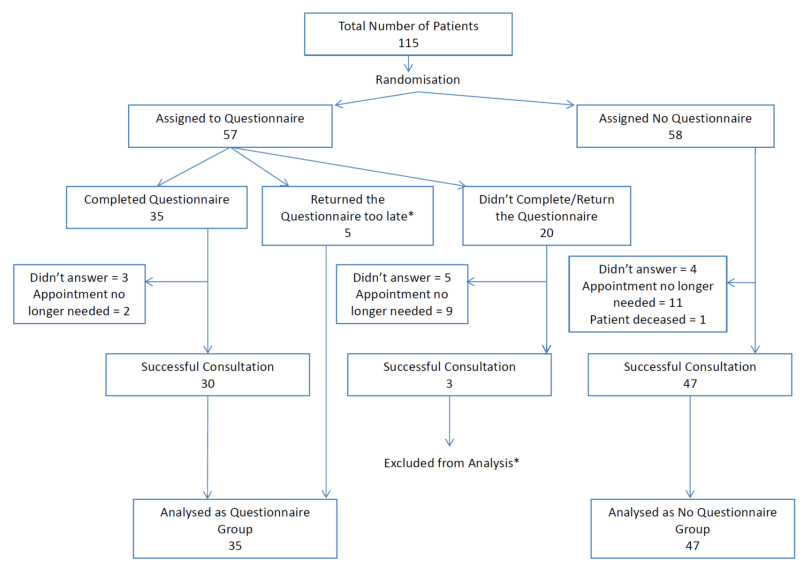

Figure 1. CONSORT Diagram 


\begin{tabular}{|c|c|c|c|}
\hline $\begin{array}{l}\text { Population (Patients who had a } \\
\text { complete consultation } n=82 \text { ) }\end{array}$ & $\begin{array}{l}\text { Questionnaire group } \\
(n=35)\end{array}$ & $\begin{array}{l}\text { No Questionnaire Group } \\
(n=47)\end{array}$ & $\begin{array}{l}\text { P-value (if } \\
\text { available) }\end{array}$ \\
\hline $\begin{array}{l}\text { Age Range }=13-95 \text { years } \\
\text { Age Mean }=59 \\
\text { Age Median }=62\end{array}$ & $\begin{array}{l}13-83 \text { years } \\
58 \\
58\end{array}$ & $\begin{array}{l}25-95 \text { years } \\
60 \\
68\end{array}$ & \\
\hline Female $=57(70 \%)$ & $23(66 \%)$ & $34(73 \%)$ & 0.629 \\
\hline $\begin{array}{l}\text { Duration of Consultation (mins) } \\
\text { Mean }=13 \\
\text { Median }=14\end{array}$ & $\begin{array}{l}13 \\
14\end{array}$ & $\begin{array}{l}13 \\
13\end{array}$ & 1 \\
\hline $\begin{array}{l}\text { Able to make a Diagnosis over } \\
\text { Telephone } \%=66 \%\end{array}$ & 27 (77\%) & 27 (57\%) & 0.0986 \\
\hline $\begin{array}{l}\text { Patient required an additional } \\
\text { face-to-face appointment }=23 \%\end{array}$ & $11(31 \%)$ & $8(17 \%)$ & 0.1855 \\
\hline $\begin{array}{l}\text { Patients required additional } \\
\text { investigations }=39 \%\end{array}$ & $9(26 \%)^{*}$ & $34(72 \%)^{*}$ & $0.0409^{*}$ \\
\hline $\begin{array}{l}\text { Patients were referred for } \\
\text { vestibular physiotherapy }=15 \%\end{array}$ & $6(17 \%)$ & $6(13 \%)$ & 0.7536 \\
\hline $\begin{array}{l}\text { Patients discharged after the } \\
\text { telephone consultation }=45 \%\end{array}$ & 18 (51\%) & 19 (40\%) & 0.3736 \\
\hline $\begin{array}{l}\text { Patients required additional } \\
\text { telephone follow-up }=32 \%\end{array}$ & $6(17 \%)^{*}$ & $20(43 \%)^{*}$ & $0.0173^{*}$ \\
\hline
\end{tabular}

*Statistically significant

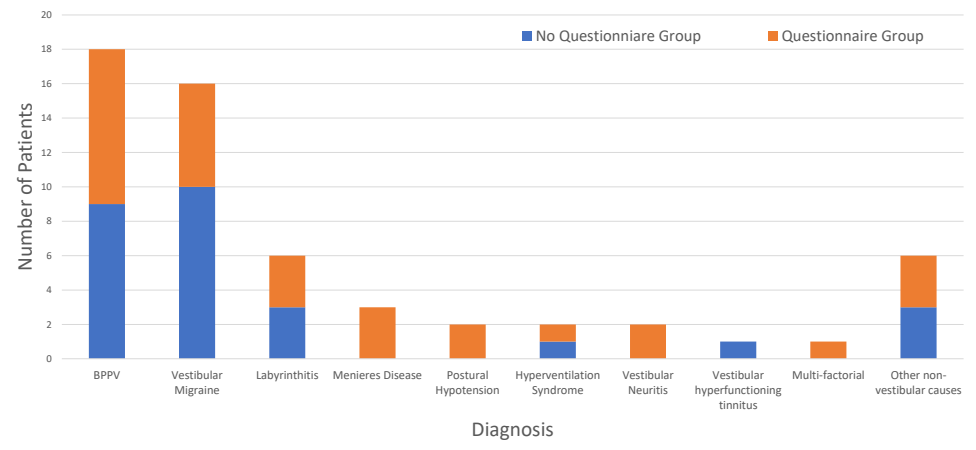

